\title{
ESTUDO DESCRITIVO E MORFOMÉTRICO DO CRÂNIO DO Ramphastos toco (AVES: PICIFORMES)
}

\section{A DESCRIPTIVE AND MORPHOMETRIC STUDY OF THE SKULL OF THE Ramphastos toco (AVES: PICIFORMES)}

\author{
Sandro Souza Caldas ${ }^{1^{*}}$ ORCID - http://orcid.org/0000-0002-3301-9555 \\ Mayara Viana Freire Gomes ${ }^{2}$ ORCID - http://orcid.org/0000-0002-7958-0073 \\ Moira Cerizza Esgalha de Andrade Silva1 ORCID - http://orcid.org/0000-0001-9355-4106 \\ Flávia Sibele Foltran Fialho ${ }^{1}$ ORCID - http://orcid.org/0000-0002-0999-588X \\ Marcelo Ismar Silva Santana ${ }^{1}$ ORCID - http://orcid.org/0000-0003-3890-047X \\ ${ }^{1}$ Universidade de Brasília, Brasília, DF, Brasil. \\ ${ }^{2}$ University of Surrey, Inglaterra, RU \\ *Autor para correspondência - sandroscaldas@hotmail.com
}

\section{Resumo}

O estudo de caracteres morfológicos e suas funções biomecânicas na estrutura craniana das aves levanta debates de cunho filogenético, taxonômico e morfofuncional. O objetivo deste trabalho foi descrever e analisar caracteres morfológicos e morfométricos do esqueleto do Ramphastos toco e confrontá-los com a bibliografia disponível. Foram analisados 13 crânios de indivíduos adultos e de um espécime dissecado fixado em formol (4\%). As carcaças foram submetidas à técnica de maceração para o preparo dos esqueletos, com a retirada dos tecidos moles, desengorduramento e clareamento em água oxigenada (50\%) e hipoclorito de sódio (50\%). O formato e amplitude da sutura naso-frontal e zona flexora craniofacial, a presença dos sesamóides intracapsulares rostral e caudal na articulação quadrática e a presença do ligamento pós-orbital foram fatores que desafiaram a bibliografia existente e os modelos de transferência de força propostos durante estudos da cinética craniana da espécie. A discussão que emerge é a possibilidade dessas características limitadoras da cinética craniana descritas nos espécimes possuírem, em conjunto, a função de promover estabilidade funcional para uma estrutura cuja natureza dimensional, em si, gera instabilidade. Os resultados morfométricos também apresentaram divergências significativas quando comparados à bibliografia disponível, o que pode estar relacionado a variáveis como especiação alopátrica, hibridização e amostragem.

Palavras-chave: Ramphastos toco. Crânio. Morfologia. Morfometria.

\begin{abstract}
The study of morphological traits and their biomechanical roles in the cranial structure of birds raises phylogenetic, taxonomic and morphofunctional debates. The aim of this study was to describe and analyze morphological and morphometric data of the skull of Ramphastos toco and to compare the results with the available bibliography. Thirteen adult skulls and one folmaldehyde-fixed dissected specimen were analyzed. For skeletal preparation, the carcasses were submitted to maceration with the removal of soft tissues, degreasing and bleaching in hydrogen peroxide $(50 \%)$ and sodium hypochlorite $(50 \%)$. The shape and size of the naso-frontal suture, the presence of the rostral and caudal intracapsular sesamoids in the quadratic joint and the presence of the orbital ligament were altogether elements that challenged the available data. It also challenges the strength transferring
\end{abstract}


models proposed in kinetic studies for the species. The discussion that emerges is the possibility of these limiting characteristics of the cranial kinetics described on the specimens have, together, a single role promoting functional stability to a structure that has a dimensional nature that generates instability. The morphometric results also presented significant divergences when compared to the available bibliography, which may be related to variables such as allopatric speciation, hybridization and sampling.

Keywords: Ramphastos toco. Skull. Morphology. Morphometric.

Recebido em: 16 de janeiro de 2017

Aceito em: 20 de agosto de 2019

\section{Introdução}

O Ramphastos toco (tucano toco, tucanuçu, tucano-boi) é uma espécie neotropical endêmica do cerrado brasileiro, que se destaca como a maior ave do gênero e também por seu bico característico. Pertencente à ordem dos Piciformes e família Ramphastidae, o tucano toco possui uma dieta substancialmente baseada em frutos carnosos, apresentando função importante como dispersora de sementes e, portanto, corroborando para manutenção da flora frutífera do ecossistema local ${ }^{(1-3)}$.

O registro fóssil mais antigo entre os Ramphastidae foi reportado por Winge ${ }^{(4)}$ e compreende fósseis das espécies $R$. dicolorus e $R$. toco. Apesar dos Piciformes serem amplamente aceitos como monofiléticos, Olson $^{(5)}$ postulou características polifiléticas para a ordem, revisitando questionamentos filogenéticos fundamentais em espécies neotropicais. O número de espécies pertencentes à família Ramphastidae também sempre foi amplamente discutido, principalmente devido à hibridização e descrição de subespécies ou raças geográficas como espécies verdadeiras, o que sublinha a necessidade de descrições sistemáticas específicas para cada espécie ${ }^{(6)}$.

O estudo de caracteres morfológicos e suas funções biomecânicas na estrutura craniana das aves tem tomado espaço novamente entre pesquisadores, levantando debates de cunho taxonômico, filogenético e morfofuncional, modificando o entendimento do crânio das aves ${ }^{(7-9)}$. Não são muitos os estudos de âmbito anátomo-morfológico da região craniana dos ranfastídeos e ainda existem divergências entre os resultados disponíveis. Burton ${ }^{(10)}$ concluiu a ausência do ligamento pós-orbital nessa família, fato questionado posteriormente por Höfling ${ }^{(11)}$, que ressalta a problemática da generalização de caracteres anatômicos em grupos taxonômicos.

O conhecimento detalhado do esqueleto das aves também é essencial para o diagnóstico de doenças do sistema locomotor e estudos de estruturas e sistemas adjacentes. Muitos profissionais médicos veterinários ainda são relutantes quanto à prática do exame radiográfico em aves, o que, segundo Arnaut $^{(12)}$, pode estar relacionado à pouca familiaridade com os métodos de contenção, anatomia básica e interpretação radiográfica. $\mathrm{O}$ pouco conhecimento da anatomia básica é agravado pela escassez de literatura específica relacionada às particularidades anátomo-radiológicas do esqueleto de aves silvestres, o que dificulta o trabalho do clínico veterinário por não contar com parâmetros referenciais adequados às diferentes espécies ${ }^{(13)}$.

O objetivo deste trabalho foi descrever e analisar caracteres morfológicos e morfométricos do esqueleto do Ramphastos toco e confrontá-los com a bibliografia disponível. Tais dados podem embasar discussões de âmbito taxonômico, filogenético e descritivo, mantendo-se os critérios 
morfofuncionais adequados.

\section{Materiais e métodos}

Para análise e comparação das estruturas anatômicas cranianas foram analisados 13 crânios adultos e um espécime dissecado fixado em formol (4\%), todos da espécie Ramphastos toco e pertencentes à coleção do Laboratório de Fisiologia e Anatomia de Animais Silvestres Faculdade de Agronomia e Medicina Veterinária da Universidade de Brasília-UnB. Os espécimes foram doados, após óbito natural, pelo IBAMA DF e não tiveram o sexo determinado.

Os espécimes dos animais foram cedidos pelo IBAMA sob os números de licença 175/2016 SUPESDF e 149/2016 SUPES-DF, para o Projeto de Pesquisa Anatomia Macroscópica - Universidade de Brasília. O projeto foi submetido à avaliação pela Comissão de Ética no Uso de Animais da Universidade de Brasília que, conforme UnBDoC n. 66686/2016, aprovou a condução do experimento.

As carcaças foram submetidas à técnica de maceração para o preparo dos esqueletos, com a retirada dos tecidos moles, desengorduramento e clareamento em água oxigenada (50\%) e hipoclorito de sódio (50\%). Durante a descrição das estruturas ósseas cranianas, os esqueletos foram submetidos à minuciosa inspeção visual. A dissecação ocorreu com o uso de pinças anatômicas, pinças hemostáticas, tesoura e bisturi, sendo rebatidos os tecidos superficiais para melhor visualização dos ligamentos da região mandibular. Globo ocular, músculos da face, tecido subcutâneo e pele foram excisados. Como descrito em trabalhos anteriores, os ossos do crânio dos espécimes de tucanos toco encontraram-se fusionados, muitas vezes impossibilitando sua delimitação. Assim, o crânio foi descrito com base em suas regiões, como adotado por Baumel ${ }^{(14)}$.

Todas as medidas da morfometria craniana foram realizadas por um único observador, utilizando paquímetro digital Starrett ${ }^{\circledR}$. As medidas foram definidas com base no trabalho de Hofling ${ }^{(6)}$, para fins comparativos. Foi empregado o teste T de Student bicaudal com um nível de confiança de 95\% para análise comparativa dos dados com a bibliografia, utilizando o programa estatístico Stata ${ }^{\circledR}$.

As dimensões cranianas utilizadas estão expostas na Figura 1. São elas: largura teto-craniana; largura entre os processos paraoccipitais; distância entre as narinas; largura da região esquimosal; altura do crânio; largura da narina; altura dorso-ventral do crânio; largura proximal da maxila; largura entre as barras jugais; largura da região exoccipital; altura dorsoventral da face caudal; largura do crânio; largura e altura do forame magno; comprimento da maxila; largura da barra jugal; comprimento da sínfise mandibular; comprimento dorsoventral do osso quadrado; ramo caudal da mandíbula; comprimento do osso pterigoide; altura da maxila; comprimento dorsal do crânio; comprimento da mandíbula; comprimento do processo ótico do osso quadrado; e altura da mandíbula.

Com o objetivo de facilitar a visualização dos dados descritos, foram obtidas representações gráficas dos crânios, com a sobreposição gráfica das mensurações realizadas (Figura 1) e de alguns acidentes ósseos. 
(A)
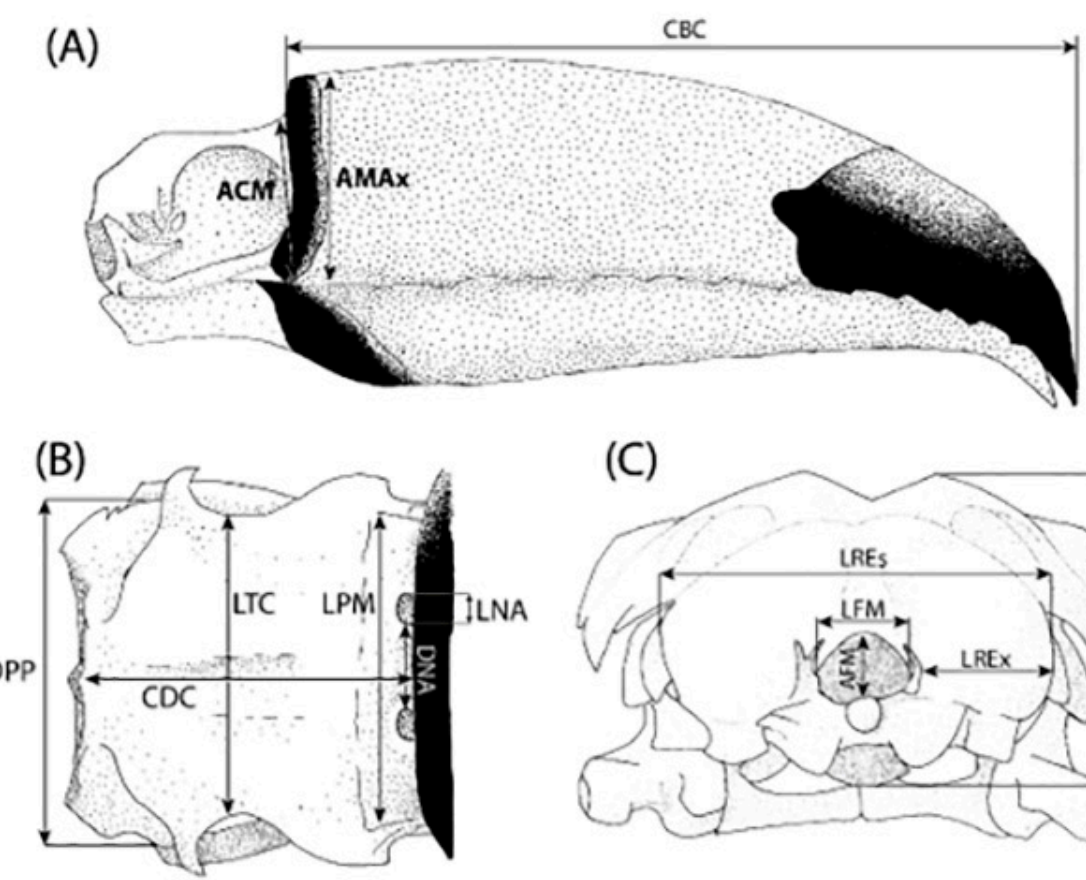

(C)

(D)
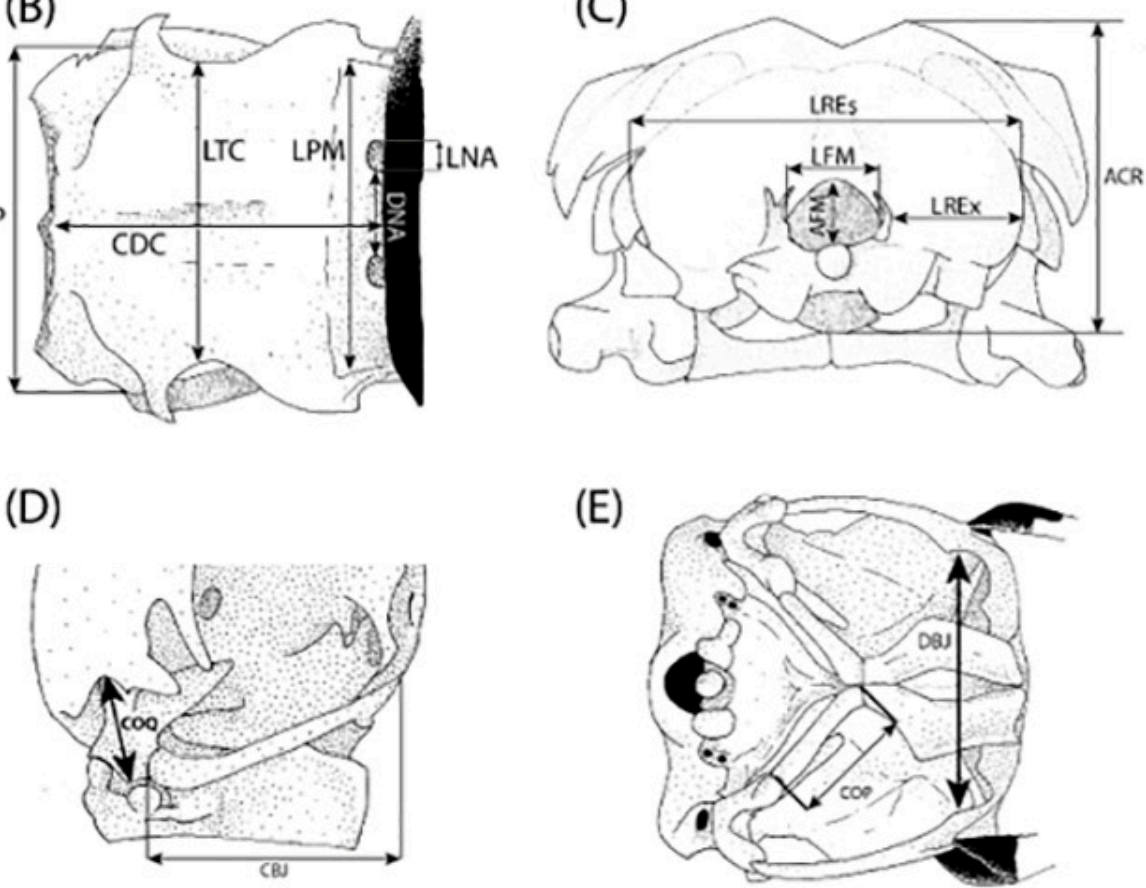

(E)

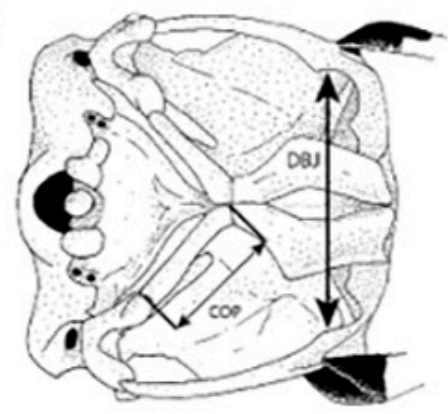

(F)
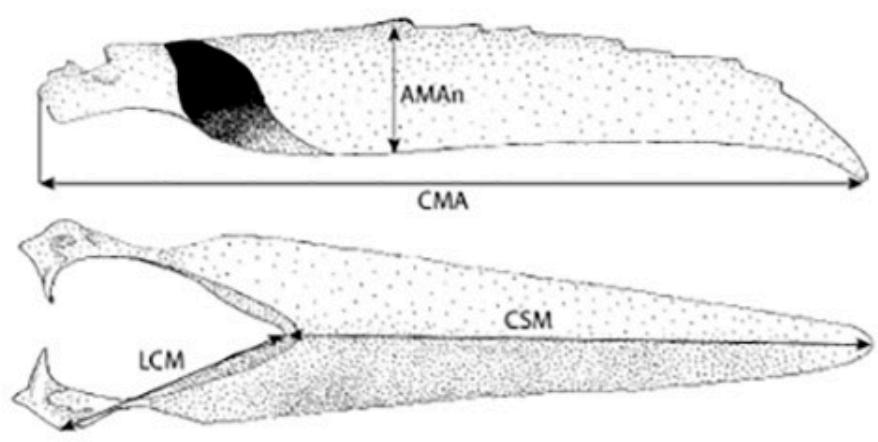

Figura 1: Fotomacrografia do crânio do $R$. toco e de todas as medidas realizadas. (A) vista lateral; (B) vista frontal; (C) vista caudal; (D) vista lateral da porção caudal; (E) vista ventral e; (F) vistas lateral e dorsal da mandibula. ACM: altura da face caudal da maxila; ACR: altura do crânio; AFM: altura do forame magno; AMAn: altura da mandíbula; AMAx: altura da maxila; $\mathrm{CBC}$ : comprimento do bico; $\mathrm{CBJ}$ : comprimento da barra jugal; CDC: comprimento dorsal do crânio; CMA: comprimento da mandibula; COP: comprimento do O. pterigoide; COQ: comprimento dorsoventral do O. quadrado; CSM: comprimento da sinfise mandibular; DBJ: distância entre as barras jugais; DNA: distância entre as narinas; DPP: distância entre os processos paraoccipitais; LCM: largura do ramo caudal da mandibula; LFM: largura do forame magno; LNA: largura da narina; LPM: largura proximal da maxila; LREs: largura da região esquimosal; LREx: largura da região exoccipital e; LTC: largura teto-craniana. 


\section{Resultados}

Sob vista dorsal, o crânio dos espécimes evidenciou as narinas holorrino imediatamente caudais ao bico (Figura 2). Apenas um dos espécimes não apresentou o forame pós-nasal. Nos demais espécimes, essa abertura, sempre recoberta por tegumento, apareceu imediatamente caudal a cada narina, tendo seu canal totalmente separado.
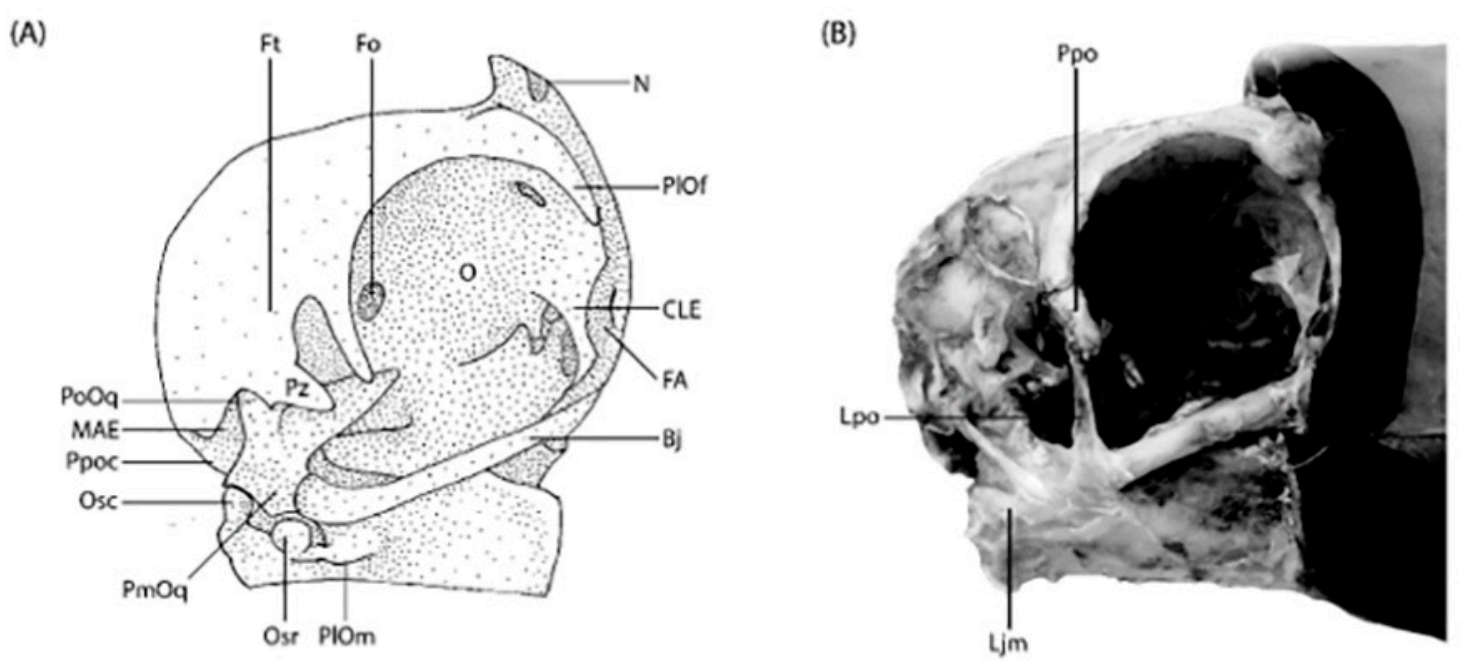

Figura 2: (A) Fotomacrografia da vista lateral do crânio do $R$. toco. (B) Registro fotográfico da vista lateral do crânio do $R$ toco, mantidos os ligamentos. N: narina direita; $\mathrm{Bj}$ : barra jugal; CLE: complexo lacrimalectetimóide; FA: fissura antorbital; Ft: fossa temporal; $\mathrm{Ljm}$ : ligamento jugo-mandibular; Lpo: ligamento pósorbital; MAE: meato acústico externo; O: órbita óssea; Osc: osso sesamóide caudal; Osr: osso sesamóide rostral; PIOf: processo lacrimal do osso frontal; PIOm: processo lateral do osso mandibula; PmOq: processo mandibular do osso quadrado; PoOq: processo ótico do osso quadrado; Ppo: processo pós-orbital; Ppoc: processo paraoccipital; Pz: processo zigomático.

A crista nucal transversa continuou como a crista nucal sagital, tomando uma posição paralela à linha sagital mediana. Também foi notada a ausência do sulco longitudinal frontal do osso frontal e uma fossa temporal caudal que não se estendeu à linha mediana, não se comunicando com o mesmo acidente contralateral. À região do limite caudal da fossa temporal houve a união entre a crista nucal sagital e a crista temporal, que seguia rostralmente à fossa temporal. A zona flexora craniofacial foi notada como uma sutura firme entre os ossos nasais e frontal.

À vista lateral do crânio (Figura 2), o processo lacrimal do osso frontal (ou osso lacrimal) se projetou latero-ventralmente, formando uma borda orbital dorso-rostral bastante regular. A parede rostral da órbita foi construída pelo complexo lacrimal-ectetimóide, um complexo amplo que se articulou com os ossos frontal e mesetimoidal. O osso ectetmóide se prolongou ventro-lateralmente em direção ao limite rostral da barra jugal, próximo à articulação desta com a maxila. Imediatamente rostral ao complexo assinalou-se a presença da fenestra antorbital, uma abertura profunda e estreita, delimitada rostralmente pela maxila. O osso mesetimoidal formou um septo interorbital completo, com demonstrada ausência do fontículo orbitocranial. Não se notaram indícios de que o osso mesetimoidal continua rostralmente para formação do septo nasal ósseo.

Ainda na face lateral do crânio, o forame óptico ocupou a região caudal da órbita, com delimitação rostral oval e um estreitamento caudal. Não foi possível definir a totalidade de ossos que participaram na formação do forame óptico, apesar de sua porção rostral adentrar a região mesetimoidal e de sua 
margem caudal conter nítida participação do osso laterosfeniodal.

O conspícuo processo pós-orbital do osso laterosfenoidal se projetou em sentido latero-ventral na região caudo-lateral da órbita e formou, em conjunto com o processo zigomático do osso escamoso, a fossa temporal rostral. Na parede caudal da órbita foi notada uma discreta elevação óssea ao nível do osso laterosfenoidal, a área muscular áspera. Caudalmente ao processo zigomático evidenciouse a região de articulação com o osso quadrado, cujo processo ótico, em conjunto com o processo paraoccipital, formou o meato acústico externo e a cavidade timpânica.

A região caudolateral (Figura 2) do crânio apresentou um osso quadrado em formato irregular, cujo processo orbital se mostrou bem desenvolvido, projetando-se em sentido rostro-medial, rumo ao septo interorbital. O processo ótico do quadrado, por sua vez, teve sua articulação com o crânio através do capítulo escamoso com uma pequena protuberância óssea arredondada, caudalmente ao processo zigomático do osso escamoso. A face caudal do processo ótico do quadrado formou a parede rostral da cavidade timpânica. O processo mandibular do quadrado apresentou três côndilos: o côndilo medial, que apresentou uma face articular convexa e lisa, articulando-se com a cótila medial da mandíbula e representando o côndilo mais desenvolvido do quadrado; o côndilo lateral, imediatamente ventral à cótila quadratojugal do quadrado, apresentou formato levemente convexo e articulou-se com a cótila lateral da mandíbula e com um osso sesamóide, denominado aqui por sesamóide rostral da articulação quadratojugomandibular; e o côndilo pterigoide que, situado na região medial ao côndilo medial, articulou-se com o osso pterigoide através de uma faceta articular convexa. A articulação entre o quadrado, a mandíbula e a barra jugal contou ainda com dois pequenos ossos discóides, sesamóides e intra-capsulares, albergados pelo ligamento jugomandibular: o primeiro situou-se entre a face lateral do osso quadrado e uma rasa faceta articular lateral à cótila lateral da mandíbula, achatandose e estendendo-se de modo que sua face cranial também articulou-se com o côndilo quadrático do osso quadratojugal, parte da barra jugal; o segundo osso sesamóide situou-se à margem caudal do quadrado, que não apresentou côndilo caudal.

O ligamento pós-orbital (Figura 2) originou-se no processo homônimo e configurou-se como uma tira fibrosa fina, continuada por uma lâmina triangulada de aponeuroses que recobriu parte da região ventro-lateral da órbita e se inseriu por toda a extensão da borda dorsal do arco jugal. O ligamento se inseriu no pronunciado processo lateral do osso mandíbula. O arco jugal, ou barra jugal, conectou o osso quadrado à maxila, apresentando-se como um osso cilíndrico, longo e livre de acidentes em seu corpo. O côndilo quadrático do osso quadratojugal - elemento anquilosado do arco - apresentou dois capítulos pouco delimitáveis para articulação com a cótila quadratojugal do quadrado e osso sesamóide rostral. Não foi notada articulação móvel entre o arco jugal e a maxila.

Sob vista caudal, o crânio evidenciou conspícua proeminência cerebelar, com ausência de delimitação entre os ossos supraoccipital e exoccipital e a presença de um par de sulcos laterais ao forame magno. Esse forame se mostrou como uma abertura ovalada, grande e acompanhado de um pequeno côndilo do occipital em sua borda ventral. Craniais ao forame magno residiram os tubérculos basilares do osso basioccipital: duas discretas proeminências ósseas ligadas medianamente pela crista basioccipital, que delimitaram a margem caudal da lâmina paraesfenoidal. Essa lâmina óssea recobriu grande parte da base externa do crânio e projetou, em ambas as margens laterais, discreta asa paraesfenoidal, que chegou a ser quase indiscriminável em um dos espécimes estudados. Imediatamente cranial à lâmina paraesfenoidal, em plano mediano, localizou-se a tuba auditiva comum, um óstio largo dividido ventralmente por uma pequena projeção óssea da lâmina. O rostro paraesfenoidal seguiu em sentido cranial à tuba, estreitando-se ao aproximar-se de seu ápice cranial. Este acidente se articulou com os ossos pterigoide e palatino através de tímido processo basipterigóide, formando uma faceta articular plana. Não houve indícios de articulação entre o rostro paraesfenoidal e o osso vômer. 
O osso pterigoide obteve posição diagonal na vista ventral do crânio (Figura 3), apresentando formato cilíndrico, livre de zonas flexoras e apresentando uma pequena projeção óssea em sua margem medial em direção à base do crânio. Em ambas as extremidades, apresentaram-se cótilas para articulação com o côndilo pterigoide do processo mandibular do osso quadrado (caudalmente) e com o processo pterigoide do osso palatino (rostralmente). O osso palatino, por sua vez, apresentou as seguintes estruturas: o processo pterigoide, que estreitou o palatino caudalmente em sua articulação com o osso pterigoide e rostro paraesfenoidal; a parte lateral, que projetou conspícuo ângulo caudomedial, em sentido caudo-lateral; e a parte coanal, que formou a fossa coanal na região mediana, estendendo-se de forma perpendicular à parte lateral, até a vista lateral do crânio, assumindo estreita relação com a região mesetimoidal do septo interorbital. O processo maxilar do palatino ocorreu já numa região inteiramente queratinizada do bico, impossibilitando sua avaliação.

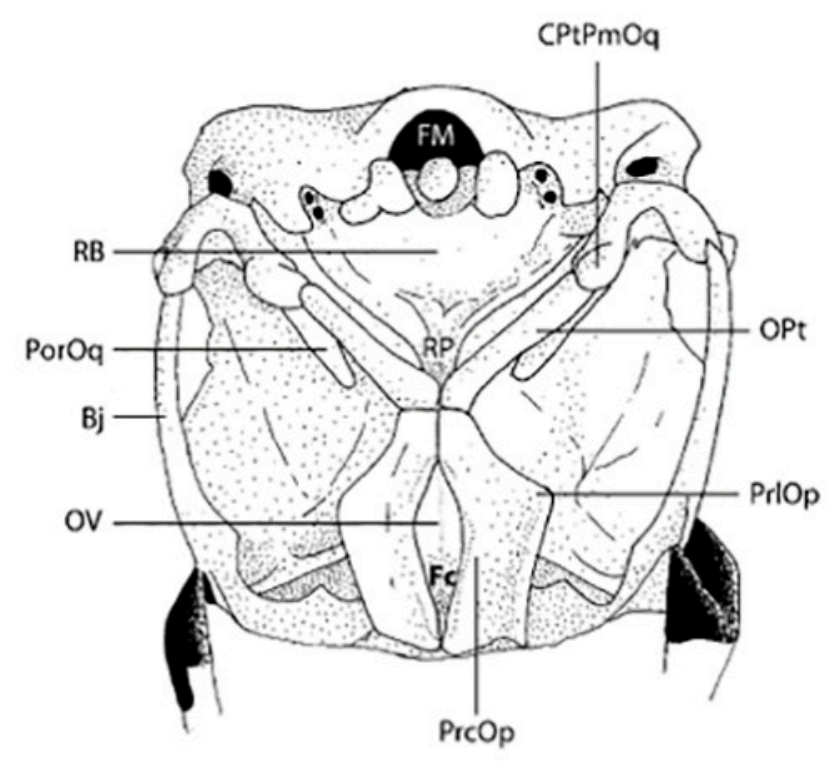

Figura 3: Fotomacrografia da vista ventro-caudal do crânio do $R$. toco. Bj: barra jugal; CPtPmOq: côndilo pterigoide do processo mandibular do osso quadrado; Fc: fossa coanal; FM: forame magno; OPt: osso pterigoide; OV: osso vômer; PorOq: processo orbital do osso quadrado; PrcOp: parte coanal do osso palatino; PrlOp: parte lateral do osso palatino; RB: região basisfenoide; RP: rostro paraesfenoidal.

O osso mandíbula se mostrou largo sob vista lateral e estreito sob vista dorsal. A região dorsocaudal da mandíbula apresentou facetas articulares de difícil delimitação, sendo elas as cótilas lateral e medial e uma breve depressão na região do sesamóide rostral, que configuraram juntas a fossa articular quadrática da mandíbula. Imediatamente rostral à articulação quadrática, o processo lateral da mandíbula serviu de inserção para o ligamento pós-orbital, de origem no processo pós-orbital. O processo retroarticular, caudal à fossa articular quadrática, aqui se mostrou pouco desenvolvido, sendo representado por uma leve inclinação da margem caudal da mandíbula, ao contrário do processo medial da mandíbula, largo e pontiagudo, que seguiu em direção medial e não se articulou com a base do crânio. Na região de seu ângulo, cranial à fossa quadrática, a mandíbula assumiu um formato largo sob vista lateral e estreito sob vista ventral, com dois pronunciados processos coronóides em sua borda dorsal, entre o terço médio e o terço rostral do osso.

A Tabela 1 dispõe os parâmetros obtidos das 22 medidas nos 13 espécimes. A Tabela 2 alinha os dados paramétricos comparados entre o presente trabalho e aquele realizado por Höfling, em 1995, utilizando o teste $t$ de Student ao testar se a diferença encontrada entre os dados é estatisticamente significativa (com 95\% de confiança). 
Tabela 1: Parâmetros morfométricos de todas as medidas dos 13 espécimes avaliados. Min.: valor mínimo; Max.: valor máximo; C.Var.: coeficiente de variação. Dados em milímetros.

\begin{tabular}{ccccccc}
\hline Medida & Média & Min. & Max. & $\begin{array}{c}\text { Desvio } \\
\text { padrão }\end{array}$ & Mediana & C. Var. \\
\hline ACM & 29,36 & 26,10 & 32,95 & 2,35 & 28,65 & 0,080 \\
ACR & 29,47 & 26,52 & 37,81 & 3,10 & 28,87 & 0,105 \\
AFM & 6,53 & 5,40 & 9,80 & 1,23 & 5,94 & 0,188 \\
AMAn & 26,03 & 23,50 & 29,27 & 1,75 & 25,62 & 0,067 \\
AMAx & 42,98 & 39,21 & 49,19 & 2,44 & 43,13 & 0,057 \\
CBC & 180,28 & 166,92 & 199,42 & 11,03 & 178,24 & 0,061 \\
CBJ & 24,67 & 22,39 & 29,47 & 2,07 & 24,17 & 0,084 \\
CDC & 35,43 & 33,22 & 40,01 & 2,41 & 34,30 & 0,068 \\
CMA & 183,89 & 163,74 & 201,85 & 11,22 & 186,70 & 0,061 \\
COP & 17,82 & 12,57 & 23,17 & 3,59 & 18,54 & 0,202 \\
COQ & 15,21 & 12,26 & 18,73 & 2,26 & 15,91 & 0,148 \\
CSM & 135,65 & 118,67 & 164,17 & 11,56 & 135,10 & 0,085 \\
DBJ & 28,87 & 20,80 & 31,72 & 3,39 & 30,34 & 0,117 \\
DNA & 10,58 & 9,95 & 11,30 & 0,43 & 10,59 & 0,040 \\
DPP & 38,20 & 29,37 & 45,48 & 5,73 & 38,36 & 0,150 \\
LCM & 52,45 & 44,53 & 60,02 & 4,12 & 52,00 & 0,079 \\
LFM & 8,72 & 6,41 & 14,45 & 2,11 & 7,94 & 0,242 \\
LNA & 5,09 & 4,11 & 6,69 & 0,66 & 5,01 & 0,130 \\
LPM & 42,48 & 36,60 & 49,84 & 3,03 & 42,67 & 0,071 \\
LRES & 36,67 & 31,69 & 39,83 & 2,29 & 36,97 & 0,062 \\
LREx & 11,50 & 9,49 & 12,53 & 0,95 & 11,68 & 0,083 \\
LTC & 37,81 & 30,02 & 41,30 & 2,74 & 38,07 & 0,072 \\
\hline
\end{tabular}

Tabela 2: Aplicação do teste t de Student para comparação entre os parâmetros encontrados e aqueles descritos por Höfling( ${ }^{(6)}$. Apenas as medidas que puderam ser reproduzidas conforme descritas por Höfling foram utilizadas. O programa estatístico utilizado para análise dos dados foi o Stataß. Dados em milimetros.

\begin{tabular}{cccccc}
\hline Medida & Média & Desvio Padrão & $\begin{array}{c}\text { Média Höfling } \\
(6)\end{array}$ & $\begin{array}{c}\text { Desvio Pad. } \\
\text { Höfling }\end{array}$ & Valor p. \\
\hline ACM & 29,36 & 2,35 & 30,91 & 2,43 & 0,14 \\
ACR & 29,47 & 3,10 & 26,27 & 1,24 & $<0,01$ \\
AFM & 6,53 & 1,23 & 5,97 & 0,37 & 0,18 \\
AMAx & 42,98 & 2,44 & 38,46 & 2,82 & $<0,01$ \\
CBC & 180,28 & 11,03 & 153,08 & 27,09 & $<0,01$ \\
CBJ & 24,67 & 2,07 & 24,04 & 1,02 & 0,38 \\
CDC & 35,43 & 2,41 & 32,85 & 1,21 & $<0,01$ \\
CMA & 183,89 & 11,22 & 162,22 & 2,54 & $<0,01$ \\
COP & 17,82 & 3,59 & 13,74 & 0,64 & $<0,01$ \\
COQ & 15,21 & 2,26 & 10,9 & 0,54 & $<0,01$ \\
CSM & 135,65 & 11,56 & 112,18 & 23,61 & $<0,01$ \\
DBJ & 28,87 & 3,39 & 33,94 & 2,13 & $<0,01$ \\
DNA & 10,58 & 0,43 & 9,81 & 0,90 & 0,01 \\
DPP & 38,20 & 5,73 & 29,68 & 1,60 & $<0,01$ \\
LCM & 52,45 & 4,12 & 49,6 & 2,40 & 0,06 \\
LFM & 8,72 & 2,11 & 7,39 & 0,75 & 0,07 \\
LNA & 5,09 & 0,66 & 4,46 & 0,60 & 0,02 \\
LPM & 42,48 & 3,03 & 39,33 & 3,42 & 0,02 \\
LREs & 36,67 & 2,29 & 31,33 & 1,24 & $<0,01$ \\
LREx & 11,50 & 0,95 & 11,64 & 0,73 & 0,70 \\
LTC & 37,81 & 2,74 & 34,96 & 2,62 & 0,01 \\
\hline
\end{tabular}




\section{Discussão}

Hall ${ }^{(15)}$ propõe a classificação do forame óptico segundo seu tamanho, que estaria ou não relacionado ao padrão de atividade visual das aves, uma vez que poderia ser um indício do tamanho do nervo óptico, responsável pela condução da informação visual da retina ao cérebro. Segundo a autora, aves noturnas apresentariam forames ópticos menores, devido à convergência de comunicação de várias células fotossensitivas em uma única célula ganglionar, diminuindo em número essas células e, assim, o diâmetro do nervo óptico, e aumentando a sensibilidade visual. No mesmo trabalho, o forame óptico de toda a família Ramphastidae é classificado como tipo 3, o que significa que o forame, apesar de discreto, seria grande demais para representar o tamanho do nervo. Pela avaliação visual, foi possível classificar o forame óptico do Ramphastos toco como pertencente ao tipo 1, sendo a abertura do forame correspondente ao tamanho do nervo, conforme proposto por Hall.

Diversas espécies de aves apresentam uma articulação naso-frontal móvel que, em conjunto com um complexo sistema de ligamentos e músculos, permite o movimento da rinoteca, independente ou não da gnatoteca ${ }^{(16)}$ e em relação ao neurocrânio, aumentando o ângulo de abertura da ranfoteca e facilitando a ingestão de alimentos ${ }^{(17,18)}$. A área articular óssea correspondente a essa articulação (zona flexora craniofacial) esteve presente em todos os espécimes de tucanos estudados.

Fisher ${ }^{(19)}$ enfatizou que a presença de uma articulação naso-frontal definida complementa a mobilidade das finas lâminas ósseas nasais, frontais e premaxilares. Höfling e $\operatorname{Gasc}^{(20)}$ e Zusi ${ }^{(21)}$ sugerem a rara situação de acinesia, onde o formato da articulação naso-frontal e o sistema de ligamentos impossibilitam a movimentação da maxila em relação ao neurocrânio. Pela dissecação dos espécimes, foi possível notar que houve movimentação da rinoteca mesmo enquanto os ligamentos permaneceram intactos.

Foi possível observar que o único ponto de articulação da rinoteca foi na articulação naso-frontal, ou seja, a forma de cinética identificada nos tucanos foi a procinese ${ }^{(21)}$. Essa é a forma mais comum entre aves neotropicais e está relacionada também às narinas tipo holorrino, presente nos tucanos. A funcionalidade procinética possibilita a movimentação da rinoteca mesmo em espécies com bicos grandes e especializados, pois cria um arco de movimentação único em torno do eixo $\operatorname{articular}^{(22)}$. Miller ${ }^{(23)}$ comenta a particularidade das forças operando no crânio do tucano durante a protração da rinoteca, em que o sistema muscular precisaria de uma articulação craniofacial ampla para garantir a unidade dos elementos ósseos da articulação da rinoteca (elementos esses: ossos pterigoide, palatino e maxila). Assim como notado por Höfling e $\operatorname{Gasc}^{(20)}$, a sutura fronto-nasal nos espécimes estudados apresentou um formato que funcionou limitando a movimentação da articulação. Sendo assim, a estabilidade no processo de transferência de forças durante a protração pode estar relacionada a outros elementos ósseos desconsiderados por Miller ${ }^{(23)}$, como aos sesamóides, e ao sistema de ligamentos.

Foi assinalada a presença dos sesamóides intracapsulares rostral e caudal na articulação do eixo quadrato-mandíbulo-jugal que, além de estabelecerem facetas articulares na região da fossa quadrática da mandíbula - limitando a movimentação do osso quadrado - adquiriram um posicionamento medial ao ligamento jugomandibular, fortalecendo-o ${ }^{(20)}$.

O osso quadrado é um dos principais eixos responsáveis pelos movimentos cinéticos cranianos ${ }^{(9,19,23)}$. O processo orbital do osso quadrado, como discutido por Pascotto ${ }^{(9)}$, pode ter a função de limitação da protração da rinoteca através de seu contato com a parede caudal da órbita. Esse processo, nos espécimes de tucano, se mostrou bastante desenvolvido. Já a área da parede caudal da órbita, com a qual o processo entraria em contato durante a cessação do movimento de protração, não apresentou acidentes ósseos significativos, apenas uma área muscular áspera pouco protuberante. Burton ${ }^{(10)}$ 
demonstrou a ausência de correlação entre o tamanho do processo orbital com o tamanho da superfície com a qual ele entraria em contato (área muscular áspera). Esse seria um indício de que o processo orbital do quadrado não apresenta função limitadora da cinética nos crânios do tucano toco.

O ligamento pós-orbital gera o ponto de tensão necessário para que a movimentação da mandíbula provoque o deslocamento cranial do osso quadrado, condicionando a protração da maxila à depressão da mandíbula, no modelo acoplado de cinética, como descrito por Hoese e Westneat ${ }^{(16)}$. A presença desse ligamento nos Ramphastidae já foi controversa. Burton ${ }^{(10)}$ caracterizou a ausência do ligamento em espécimes da família. Prum ${ }^{(24)}$ trouxe a hipótese de que essa característica seria uma sinapomorfia das famílias Ramphastidae e Captonidae. Höfling ${ }^{(6)}$ observou o ligamento em $R$. dicolorus, $R$. vitellinus e $R$. tucanus, confrontando os resultados de Burton ${ }^{(10)}$. Höfling também descreveu o ligamento pósorbital em $R$. tucanus como associado a aponeuroses da região, descrevendo uma zona de espessamento das aponeuroses que configura uma condição intermediária entre aponeurose e ligamento. Em muitas espécies de aves neotropicais modernas o ligamento pós-orbital de fato é vestigial, já nos espécimes de $R$. toco aqui avaliados foi sublinhada a presença do ligamento associado às aponeuroses da região. A presença do ligamento embasa a existência da cinética acoplada, como já discutido ${ }^{(10,25,26)}$.

A articulação entre o rostro paraesfenoidal e os ossos pterigoide e palatino limitariam a cinética craniana, uma vez sendo necessária a movimentação em pivô do pterigoide para a completa transferência de força entre o quadrado e a maxila ${ }^{(27)}$. Assim, a discussão que emerge é a possibilidade dessas características limitadoras da cinética craniana descritas no Ramphastos toco terem, em conjunto, a função de promover estabilidade funcional para uma estrutura cuja natureza dimensional, em si, gera instabilidade.

As consequências funcionais desse arranjo craniano estão associadas ao comportamento alimentar do tucano - que inclui frutos carnosos, ovos, filhotes de animais, insetos e flore ${ }^{(1,2,28,29)}$. Como descrito por Mikich ${ }^{(30)}$, à apreensão do alimento essas aves jogam a cabeça para cima e para trás, de modo a lançá-lo para o interior da cavidade oral, mesmo sem ampla abertura da ranfoteca. Ao se alimentar de frutos carnosos, a ave pode realizar uma manobra que consiste na ligeira abertura do bico para, então, enterrá-lo na fruta retirando a parte da polpa que fica represada no bico, sendo essa a porção deglutida. Essa manobra é auxiliada pela margem serrilhada e o formato de losango do bico. O tucano apresenta ainda outros comportamentos de fragmentação das presas que poupam a utilização do bico, como o roçar do alimento em galhos e outras estruturas rígidas, utilizando os membros ${ }^{(30)}$. Dados quanto a modelos mecânicos da cinética craniana dos Ramphastidae são escassos. Miller ${ }^{(23)}$, em sua tentativa de esclarecer essas questões, se deparou com a falta de uma descrição morfológica coesa entre a literatura disponível, desconsiderando caracteres importantes na construção dos modelos. Sugeremse aqui estudos nesse âmbito a fim de esclarecimento de alguns padrões etológicos da espécie. $\mathrm{O}$ ato de inclinar a cabeça para trás ao ingerir grandes presas, por exemplo, pode estar associado a modelos de força alternativos, possibilitando a movimentação da rinoteca sem desestabilizar os elementos morfológicos relacionados à cinética craniana.

Tattersall ${ }^{(31)}$ discute amplas funções biológicas relacionadas ao tamanho do bico na espécie, como a de descascar frutos, predação de ninhos, termorregulação, seleção social e alerta visual. A importância da seleção social entre os Ramphastos é discutida por West-Eberhard ${ }^{(32)}$, que evidencia o extraordinário bico do grupo como protagonista em comportamentos de combate. A seleção também é caracterizada como não-sexual, já que ambos os sexos apresentam esse tipo de comportamento. West-Eberhard também propôs que o mecanismo de seleção de indivíduos vai além da escolha para acasalar. Esse mecanismo também engloba, por exemplo, o processo de favoritismo dentro da prole, onde os pais podem realocar recursos essenciais para filhotes com determinado fenótipo ${ }^{(33)}$. Dentro do contexto da seleção social, e considerando o comportamento altamente social do Ramphastos toco, esse processo 
de seleção ou escolha de indivíduos também poderia ser ampliado para a delimitação de grupos sociais, nos quais determinadas características - como o tamanho do bico ou coloração - favoreceriam a sociabilização de determinados indivíduos. Sugerem-se estudos experimentais nesse âmbito. Assim, no decorrer da exposição dos resultados morfométricos do presente trabalho, o leitor deve manter em mente a amplitude dos critérios da sistemática filogenética e processos evolutivos, considerando a possibilidade de seleções por competições intraespecíficas (como no caso da seleção social).

Em estudos morfométricos do crânio, Höfling ${ }^{(6)}$ comenta o uso de coeficientes de variabilidade como indicadores de pressões de seleção em populações de aves. A existência de dimorfismo sexual quanto a parâmetros morfométricos na espécie ainda é discutida ${ }^{(6,34,35)} \mathrm{e}$ foi desconsiderada aqui. As medidas com maior coeficiente de variação foram LFM, AFM, COQ, COP, LNA, DBJ, DPP e ACR. Esses resultados diferiram dos de Höfling ${ }^{(6)}$, que apontou LFM, COQ e COP como caracteres conservativos e espécie específicos. Essa divergência pode estar associada ao processo de especiação alopátrica, apesar de não existirem dados quanto às regiões de procedência dos animais. A discrepância dos dados evidencia a dificuldade de definir parâmetros morfométricos sinapomórficos e robustos para uma espécie com tamanha gama de hibridização e especiação, principalmente quando é inviável o agrupamento de grandes amostras ${ }^{(11,24,36)}$.

A Tabela 2 dispõe os dados paramétricos comparados entre o presente trabalho e aquele realizado por Höfling ${ }^{(6)}$, utilizando o teste t de Student para testar se a diferença encontrada entre os dados é estatisticamente significativa (com 95\% de confiança). Apesar de a hipótese nula não ser refutada em LFM, as medidas COQ e COP foram estatisticamente diferentes daquelas encontradas por Höfling. De fato, apenas 6 das 21 medidas comparadas não refutaram a hipótese nula.

A média da relação entre CSM e LCM (CSM/LCM+CSM) encontrada nos espécimes foi 0,7206, próxima à encontrada por Höfling ${ }^{(6)}$, que foi 0,6869 . No mesmo trabalho, Höfling encontrou uma relação de 0,7044 para Ramphastos tucanus, a maior relação entre as espécies consultadas, além de encontrar uma média de tamanho do bico (CBC) maior nessa espécie. Os resultados encontrados nos espécimes aqui estudados demonstram um comprimento de bico maior que os analisados por Höfling, tanto em $R$. toco quanto em $R$. tucanus. Esses resultados corroboram a bibliografia disponível, que classifica o bico do $R$. toco como o maior entre os Ramphastidae ${ }^{(37)}$. A divergência nos resultados pode estar associada ao reduzido tamanho da amostra de $R$. tucanus, mas também à hibridização e especiação - como já discutido.

Vale ressaltar que, assim como no presente trabalho, Höfling ${ }^{(6)}$ optou por não definir subespécies para os espécimes estudados. A delimitação de caracteres de subespécies é arriscada em amostras pequenas de regiões vastas. Esses fatores são ainda mais problemáticos quando lidamos com um bioma tão complexo e fragmentado quanto o cerrado, com alta variação geográfica e áreas dispersas de endemismo associadas a uma ocupação antrópica em larga escala ${ }^{(38,39)}$. Patané(3) cita duas subespécies: $R$. toco toco e $R$. toco albogularis, descrevendo um bico menor como característica da última, com a ressalva de existirem muitas variações entre as subespécies.

As informações apresentadas neste estudo visaram contribuir para a descrição da espécie Ramphastos toco, com ocorrência na região Centro-Oeste do Brasil. É importante ressaltar que o conhecimento da variação das populações de aves nas diversas regiões neotropicais oferece subsídios para a identificação e caracterização das espécies, realizada com parâmetros morfológicos e morfométricos cranianos. Resultados apresentados, como o formato e amplitude da sutura naso-frontal e zona flexora craniofacial, a presença dos sesamóides intracapsulares rostral e caudal na articulação quadrática e a presença do ligamento pós-orbital, foram fatores que desafiaram a bibliografia existente e os modelos de transferência de força propostos durante estudos da cinética craniana da espécie. Resultados 
morfométricos, como o comprimento do osso pterigoide e o comprimento dorsoventral do quadrado, também demonstraram divergências quando comparados à bibliografia disponível, o que pode estar relacionado a variáveis como especiação alopátrica e hibridização.

\section{Referências}

1. Galetti M, Laps R, Pizo MA. Frugivory by toucans (Ramphastidae) at two altitudes in the Atlantic forest of Brazil. Biotropica, v. 32, n. 4, p. 842-850, 2000.

2. Ragusa-Netto J, Fecchio A. Plant food resources and the diet of a parrot community in a gallery forest of the southern Pantanal (Brazil). Braz. J. Biol., v. 66, n. 4, p. 1021-1032, 2006.

3. Patané JSL et al. Molecular Phylogenetics and Evolution. Molecular Phylogenetics and Evolution, Vol.53. p.923-934, 2009.

4. Winge O. Flugel fra knoglehuler i Brasilien. Museo Lundii, 54p, 1887.

5. Olson, S.L. Evidence for polyphyletic origin of the Piciformes. Auk, Washington, v. 100, n. 1, p. 33-126, 1983.

6. Höfling E. Anatomia do crânio e da cintura escapular dos Ramphastidae (Aves: Piciformes) e de alguns grupos próximos, com implicações sistemáticas. Tese (Livre-Docência). Universidade de São Paulo, 1995.

7. Simonetta AM. On the Mechanical Implications of the Avian Skull and Their Bearing on the Evolution and Classification of Birds. The Quarterly Review of Biology, Vol. 35, No. 3, 1960. pp. 206-220.

8. Zweers GA. Cranial kinesis in birds: Consequences for the evolution of the jaw apparatus. In: Adams, N.J. \& Slotow,RH. (eds), Proc. 22 Int. Ornithol. Congr., Africa, pp. 82-93. 1999.

9. Pascotto MC et al. Osteologia craniana de Coraciiformes (Aves). Rev. Bras. Zool. vol.23 no.3, Curitiba, 2006.

10. Burton PJK. Anatomy and evolution of the feeding apparatus in the avian orders Coraciiformes and Piciformes. Bulletin of the British Museum (Natural History), Londres, Vol. 47, N. 6, pag. 331-443. 1984.

11. Höfling E. Recent anatomical studies on neotropical birds. Ornitologia Neotropical, 15 (Suppl.): 73-81, 2004.

12. Arnaut LS, 2006: Estudo radiográfico das afecções do sistema esquelético em aves. M.V.Sc. Thesis: Faculdade de Medicina Veterinária e Zootecnia - Departamento de Cirurgia, Universidade de São Paulo. Disponível em: http://www.teses.usp.br/teses/disponiveis/10/10137/tde-06032007-140542/publico/LucianadosSantosArnaut. $\underline{\mathrm{pdf}}$

13. Goulart CES, 2006: Valores hematológicos de referência para papagaios verdadeiros (Amazona aestivaPsittacidae) mantidos em cativeiro. M.V. Sc. Thesis: Universidade Federal de Minas Gerais. Disponível em https://repositorio.ufmg.br/bitstream/1843/HESA-6ZWPQV/1/disserta_o_carlos_goulart.pdf

14. Baumel, J J. 1993: Nomina Anatomica Avium. Nuttall Ornithological Club, Cambridge.

15. Hall MI, Iwaniuk AN, Gutiérrez-Ibáñez CN. Optic Foramen Morphology and Activity Pattern in Birds. The Anatomical Record, Vol. 292, pp. 1827-1845. 2009.

16. Hoese WJ, Westneat MW. Biomechanics of cranial kinesis in birds: testing linkage models in the whitethroated sparrow (Zonotrichia albicollis). J. Morph. v.227, 305-320, 1996. 
17. Berger AJ. Anatomical Variation and Avian Anatomy. University of California Press on Behalf of the Cooper Ornithological Society, v.58, n.6, p. 433-441, 1956.

18. Getty R. Anatomia dos Animais Domésticos. 5ed., v.2, 1986, p.1680-1684.

19. Fisher, H. I, Some aspects of the kinetics in the jaws of birds. The Wilson Bulletin. 67, 175-188. 1955.

20. Höfling E, Gasc JP. Biomechanics of the skull and the beak in Ramphastos (Ramphastidae, Aves) I. Description of anatomical elements]. Gegenbaurs Morphol Jahrb. 130 (1) 125-47, 1984.

21. Zusi RL. Patterns of diversity in the avian skull. In: Hanken, J., Hall, B.K., The Skull. Patterns of Structural and Systematic Diversity, vol. 2. University of Chicago Press, Chicago, USA, pp. 391-437. 1993.

22. Zusi RL. A functional and evolutionary analysis of rhynchokinesis in birds. Smithson. Contrib. Zool., n. 395, p. 1-40, 1984.

23. Miller SSBA. Dynamical models of cranial kinesis. Tese (Mestrado em Matemática) - Graduate Faculty of Texas Tech University, Maio, 2002. Disponível em https://tu-ir.tdl.org/ttu-ir/bitstream/ handle/2346/9705/31295017082255.pdf? sequence $=1$

24.PrumRO.Phylogeneticinterrelationshipsofthebarbets(Aves:Capitonidae)andtoucans(Aves:Ramphastidae) based on morphology with comparisons to DNA-DNA hybridization. Zoological journal of the Iinnean society, 92: 313-343. 1988.

25. Bock WJ. Kinetics of the avian skull. J. Morphol. Vol.114, Ed.1, 1964.

26. Bout RG, Zweers GA. The role of cranial kinesis in birds. In: Comparative Biochemistry and Physiology, Part A. Institute of Evolutionary and Ecological Sciences, The Netherlands, p. 197-205. 2001.

27. Brusaferro A, Simonetta AM. Morphology of the feeding apparatus in nestlings of Merops. Italian Journal of Zoology. Vol.65, 249-259. 1998.

28. Mindell DP, Black HL. Combined-effort hunting by a pair of Chestnut-mandibled Toucans. Wilson Bull, v. 96, n. 2, p. 319-321,1984.

29. Short LL, Horne JFM. Family Ramphastidae (Toucans). In: delHoyo, J.; A. Elliot \& J. Sargatal (eds.). Handbook of the Birds of the World. Vol 7.Jacamars to Woodpeckers. Lynx Edicions: Spain, Pp 220-272, 2002.

30. Mikich SB. Etograma de Ramphastos toco em cativeiro (Piciformes: Ramphastidae). Ararajuba, Revista Brasileira de Ornitologia, v.2, p.3-17, 1991.

31. Tattersall GJ et al. Heat Exchange from the Toucan Bill Reveals a Controllable Vascular Thermal Radiator. Science, v.325, 468, 2009.

32. West-Eberhard MJ. Sexual Selection, Social Competition, and Speciation. Q. Rev. Biol. 58, 155, 1983.

33. Tobias JA. et al. The evolution of female ornaments and weaponry: social selection, sexual selection and ecological competition. Phil. Trans. R. Soc. B, v.367, 2012.

34. Höfling E. Étude comparative du crâne chez des Ramphastidae (Aves, Piciformes). Bonner Zoologische Beitraege 42: 55-65. 1991.

35. Castro MS. et al. Sexual dimorphism in Ramphastos toco and Ramphastos dicolorus (Piciformes, Aves). Rev. biol. Trop, vol.51, n.1, 2003.

36. Endler JA. Geografic variation, speciation and clines. Syst. Zool., 27 (4), p 482-483, 1978. 
37. Alvarenga H. Toucans of the Americas. M. Pontual Edições e Arte, Rio de Janeiro, Brazil, 2004.

38. Leite L. O. Análise de endemismo, variação geográfica e distribuição potencial das espécies de aves endêmicas do cerrado. Tese: doutorado em biologia animal, Universidade de Brasília, 2006. Disponível em: http://repositorio.unb.br/handle/10482/6556

39. Roma JC. A fragmentação e seus efeitos sobre aves de fitofisionomias abertas do Cerrado. Tese: doutorado em ecologia, Universidade de Brasília, Brasília, 2006. Disponível em: http://repositorio.unb.br/ bitstream/10482/6444/1/Tese\%20Julio\%20Cesar\%20Roma.pdf 